\title{
A SIMULATION MODEL TO EVALUATE AN EMERGENCY RESPONSE SYSTEM FOR OFFSHORE HELICOPTER DITCHES
}

\author{
Markus Brachner \\ Department of Business Administration and \\ Social Sciences \\ Harstad University College \\ P O Box 1063, 9480 Harstad \\ NORWAY
}

\begin{abstract}
A simulation model that supports the planning of an offshore emergency response system is presented. This model is based on official guidelines for offshore preparedness and can be used to evaluate different designs of an emergency system in respect to quantity, performance and location of Search-and-Rescue helicopters by modeling the coverage of the area under consideration. The model is trace-driven by means of environmental data. It includes a number of stochastic parameters which show a complex system of location dependence and interdependency. As a result a heat-map to visualize the response capacity and its service level is generated. The petroleum industry in Norway is expected to move into new areas. One particular area of interest is the Barents Sea, which is characterized by long distances and challenging environmental conditions. A case study which shows possible designs of an emergency response system in this area using the simulation model is presented.
\end{abstract}

\section{INTRODUCTION}

The Norwegian oil and gas industry heavily relies upon helicopters as means of personnel transportation to offshore facilities. At the same time, helicopter transport is considered to be one of the major hazards for employees in this industry. This will be a particular challenge for the Arctic Region, which has received increased attention in respect to offshore oil and gas exploration, but has established neither necessary infrastructure for regular production nor an emergency response system (ERS) to react in case of incidents. There, long distances and averse environmental conditions will increase risks connected to offshore personnel transportation and will make emergency response more difficult than in any of the established areas. Polar lows, for example, can be short lived and difficult to detect, and are a hazard for operations in this latitude. Three months of permanent darkness during the winter are not only a psychological challenge, but can increase the time for rescue operations. Low sea temperatures are life threatening for persons in distress and limit the time to respond to an incident.

While the petroleum industry has seen emergency preparedness for a long time as an isolated issue for every installation, one of the most significant changes in offshore preparedness over the last 15 years is the introduction of an area preparedness concept. Thus, response planning would not be considered just on per-installation basis, but emergency resources are used to cover a certain area as far as minimum requirements can be fulfilled. The most important criterion for delimitation of preparedness areas for Search-and-Rescue (SAR) operations is the requirement to be able to rescue 21 people in the sea within 2 hours (Vinnem 2011).

With particular attention to the Arctic region and its challenges a simulation model for evaluating the emergency preparedness was developed. This model involves a systems perspective, taking the environmental conditions and interplay of available resources with their technical specifications into account. The model 


\section{Brachner}

can be used to evaluate variants of ERS designs and the robustness of the resulting coverage. This is particularly important as whole routes to the installations need to be covered. Thus feasible ERS designs should always allow routes between an onshore base and an offshore location that are entirely within safe ares. Heat-maps as one of the outputs of the simulation show the areas which can be covered with a required capacity at a minimum accepted probability on a map.

This paper is structured as follows. Similar problems in scientific literature are reviewed in Section 2. Then the problem and the underlying guidelines are described in Section 3. From this a mathematical formulation of the simulation model is derived in Section 4. After a short description of the technical realization in Section 5, results of a case study in the Barents Sea on the basis of the this model are presented in Section 6. The paper concludes with remarks and further opportunities for research in Section 7.

\section{LITERATURE REVIEW}

The rescue capability for operations in the Barents Sea has been discussed by Jacobsen and Gudmestad (2013). A combination of a SAR helicopter and multipurpose emergency response vessels is proposed as a rescue scheme. A deterministic model for the capacity calculation is used, and the scheme is valid for a single route which runs as a straight line between an onshore base and an offshore location.

Simulation could be considered as a valuable tool in planning emergency preparedness systems for the offshore industry. Yet, most of developed models have concentrated on oil spill incidents. OSCAR (Reed, Aamo, and Daling 1995), for example, is a tool to assess alternative oil spill strategies. It has already been in use for a long time and has been steadily improved since its first version. More recently, Li et al. (2014) combined a Monte Carlo simulation and optimization to provide decision support for devices allocation and recovery operation during offshore oil spill responses.

When planning new installations in Norway and the UK, emergency preparedness has to be evaluated through a Probabilistic Risk Assessment studies. These are often not very detailed. Various approaches in scientific literature were developed that allow for more detailed analysis. Yun and Marsden (2010) present a methodology based on event trees and Monte Carlo simulation to evaluate the robustness of Escape, Evacuation, and Rescue strategies. Event tree analysis provides quantitative results and allows for interdependent variables. Vinnem (2011) points out that the cases where emergency preparedness solutions had to stand the test of reality rarely occur. Compared to other incidents, however, helicopter accidents and ditches still have been somewhat more frequent. He combines quantitative and qualitative data of different preparedness topics and consolidates the results to draw a picture of the overall preparedness status. This approach is rather an a posteriori evaluation of a preparedness system already in place. Norrington et al. (2008) model the reliability of Search-and-Rescue operations by identifying the primary variables and bringing them together in an Bayesian Belief Network (BBN). While the construction of the BBN resulted in a deeper understanding of the key factors, this did not result in a valid quantitative output. The closest approach to the one presented may be the software Offshore Sea Rescue, which simulates the rescue of people in distress at sea (Soma, Haugen, and Øygarden 2003). While the survival times are a function of sea temperature and clothing in this model, the user has to specify transit times and environmental conditions.

The presented model has features related to facility location and coverage problems, where a research stream can be found in the field of optimization ( $\mathrm{Li}$ et al. 2011). Stochastic factors can be included into these models; e.g., Berman, Hajizadeh, and Krass (2013) explore the maximum covering problem with travel time uncertainty in order to find the optimal location facilities for fire stations, such that fire trucks can be on the incident site within a certain amount of time. The authors mention, that the solution quality of deterministic models can be very poor. Ingolfsson, Budge, and Erkut (2008) present a model to minimize the number of ambulances, that can fulfill a specified service level as the fraction of calls reached within a given time standard. Mobilization and travel time are modeled as stochastic variables.

The literature research did not reveal a similar personnel SAR model, that is able to evaluate the ERS performance of existing and new installations under stochastic capacity, which is a result of interdependent stochastic transit and pickup times. 


\section{Brachner}

\section{PROBLEM DESCRIPTION}

The presented model is based on the guidelines of the Norwegian Oil and Gas Association for establishing area preparedness (Norsk olje og gass 2012). These guidelines describe a set of defined hazards and accidents (DFU, as an acronym of the Norwegian term Definerte Fare- og Ulykkessituasjoner), which need to be considered for planning and dimensioning the preparedness system for offshore oil and gas facilities.

The model simulates particularly the DFU Person in sea as a consequence of a helicopter accident. A situation like this can arise, when personnel is transported by helicopter from or to an offshore platform, and the helicopter needs to ditch on the way. While it is possible for helicopters to float in sea conditions within certain limits, immediate capsizing has to be considered as the dimensioning scenario. Passengers and pilots do wear immersion suits, which protect them from hypothermia, however the effect is restricted over time.

According to the aforementioned guidelines, the available capacity has to be sufficient to rescue a full transport helicopter within 120 minutes. While this capacity can be provided by one response unit (RU), several RUs can cooperate to fulfill the requirement as well. RUs are usually SAR helicopters, in some cases specialized vessels are used in addition. The different time components of a response are shown in Figure 1. In case of an incident the Emergency Control Center is called and the necessary RUs are dispatched. A certain mobilization time elapses until they can leave. The mobilization time for SAR helicopters for offshore preparedness is usually agreed to be at a maximum of 15 minutes. The RUs will begin their travel to the incident site.

When the RUs arrive, the accomplishment phase starts by picking people in distress out of the sea. The pick-up time is considered to be dependent on the significant wave height $H_{s}$ and visibility. As an addition to the above mentioned guideline, the Norwegian Oil and Gas industry published the underlying assumptions (Vinnem 2012). For the presented model, an adapted version of these values are used (see Table 1), because the pick-up time in the dark for $H_{s}>6$ was found to be too conservative, changing this value to 4 minutes (Kråkenes et al. 2013).

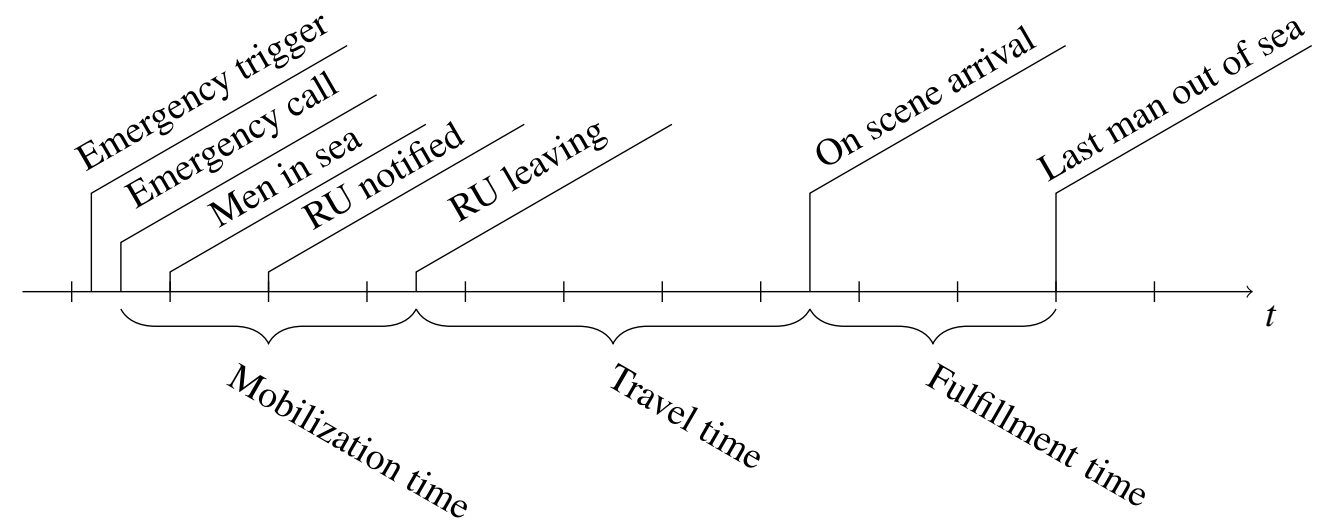

Figure 1: Time components of a response for one RU

Table 1: Helicopter pickup times dependent on significant wave height $\left(H_{S}\right)$ and light conditions

\begin{tabular}{|l|c|c|}
\hline & Daylight & Dark \\
\hline Waves $<6 \mathrm{~m}\left(H_{s}\right)$ & $2 \mathrm{~min}$ & $3 \mathrm{~min}$ \\
\hline Waves $>6 \mathrm{~m}\left(H_{S}\right)$ & $3 \mathrm{~min}$ & $4 \mathrm{~min}$ \\
\hline
\end{tabular}

Further on, we will refer to the rescue capacity for an incident site as the number of people that can be picked up from the sea within a given time limit. This rescue capacity is stochastic. While a multitude of 


\section{Brachner}

sources of stochasticity could be identified, the focus in this paper is on the environmental conditions as wind speed and direction, wave height, and daylight. Wind conditions influence the travel time of a RU, and the pickup time depends on the wave height at the incident site.

Moreover, additional RUs within the preparedness system increase the complexity. First, the cooperative aspect needs to be considered, as the capacity for several RUs on site is not simply additive. An overhead of coordination between RUs decreases the additional rescue capacity obtained by adding one resource. In the aforementioned guidelines this is accounted for by a reducing the pick-up rate of every additional RU by $50 \%$. While the first RU on site has, e.g., a pick-up time of 3 minutes per person, any additional RU will only be able to pick up people every 6 minutes.

Second, the contributed rescue capacity of two RUs is expected to be not independent from each other, which makes it difficult to model it or its components as probability distributions. Several interdependencies can be observed. As explained earlier, the pick-up time is dependent on the on-site wave height and daylight conditions. Since every RU is exposed to the same environmental conditions on site, the interdependency is evident for this component.

Another interdependency, however, was expected between travel time of two different RUs. This can be understood by the scenario visualized in Figure 2. There are three RUs, positioned at the locations Hammerfest, Alpha and Bjфrnфya-B respectively. For the exact locations see Figure 5. All of them have the same distance to an assumed incident site Castberg. Assuming wind as shown in the figure, the RU from Hammerfest will travel with head wind, which will slow it down, while the RU from Bjørnøya-B will experience a speed increase over ground. The RU positioned at Alpha, however, will mostly experience the same environmental conditions as the RU at Hammerfest. This leads to the assumption, that the travel times of the RUs from Hammerfest and Bjørnøya to the incident site could be negatively correlated, while travel times from Hammerfest and Alpha seem to be positively correlated.

One more inter-dependency should be mentioned. Wind and wave height are closely coupled to each other through the wind-wave mechanism (Komen et al. 1996, p. 60). Therefore, travel time and pickup time could show some degree of inter-dependency.

This complex interplay of stochasticity and interdependency lead us to the approach of a trace-driven simulation. This does, however, not necessarily mean, that real life data is used: The weather data, which is part of the input data, is already an output of a weather model.

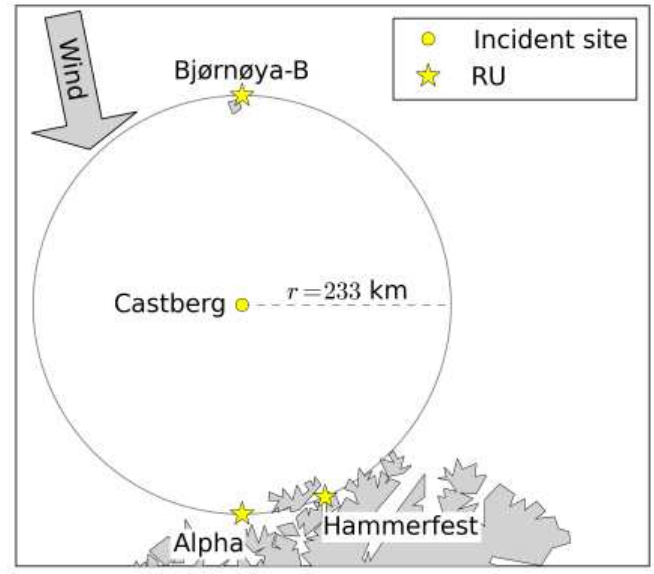

Figure 2: Scenario

\section{MODEL DESCRIPTION}

The high number of points to calculate in order to generate a heat map require an efficient execution of the simulation model. Initially an approach using Discrete Event Simulation was considered. This, however, 


\section{Brachner}

turned out to be too slow. Therefore, an alternative method was chosen, involving multiple stages of matrix operations: Ahead of execution the input data is prepared and preprocessed where possible and reasonable. During the execution the model goes through the phase of travel simulation for each RU, further on to the response simulation involving all available RUs, and finally the consolidation.

\subsection{Input data}

The model takes the environmental conditions for every point on the simulation grid at discrete, evenly distributed points in time $t$ during a defined timespan $T$ as an input. Waves are represented in terms of significant wave height $H^{\text {sig }}$, which is defined as the mean wave height of the highest one-third of waves observed (Holthuijsen 2007, p. 28) and commonly used to describe the sea state. $H^{\text {sig }}$ for a point $(x, y)$ at a point in time $t$ will be later on denoted as $H_{t x y}$. Furthermore, binary values $L_{t x y}$ indicate the daylight at time $t$ and point $(x, y)$. 0 stands for darkness, 1 for light. Wind speed and direction are given and denoted as $\vec{W}_{t x y}$.

Moreover, a set of RUs $R$ with locations $L_{r}$, and the maximum true airspeed (TAS) $S_{r}$ for every $r \in R$ is given. TAS is defined as the speed of the aircraft relative to the air mass. Finally, the mobilization time $t^{\mathrm{mob}}$ and the time limit for a person in sea $t^{\mathrm{max}}$ is given.

\subsection{Travel Simulation}

The travel of an aircraft can be described as a relative movement to the airmass in which it is flying. As the helicopter is moving through the air as its medium, the air movement determines the helicopter speed related to the ground. Wind speed can be considerable and taking this factor into account when evaluating a preparedness system adds therefore an important perspective.

The travel simulation deserves particular attention, because it is the computationally most expensive operation in the simulation. A high number of repetitive operations are needed, and the speed of these operations can be decisive for the overall computational time.

In order to reduce this time, the travel of each RU is simulated from its initial position radially for a defined number of rays $n^{\max }$, maintaining a constant course $c(n)=\frac{360 n}{n^{\max }}$ for the $n^{\text {th }}$ ray, until the map bounds are reached or $t^{\max }$ is exceeded, such that the RU can not have an effect anymore in the fulfillment phase (Figure 3a). After this, the travel time to each point in the simulation grid is interpolated (Figure 3b).

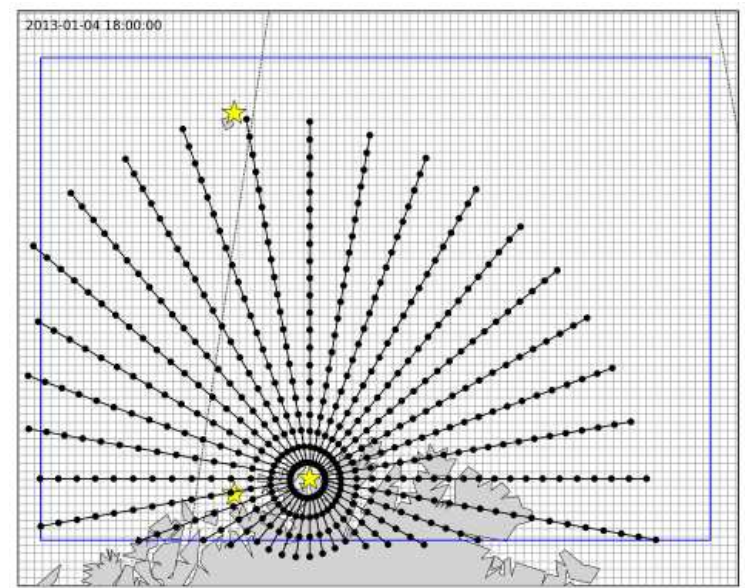

(a) Radial travel simulation from initial location

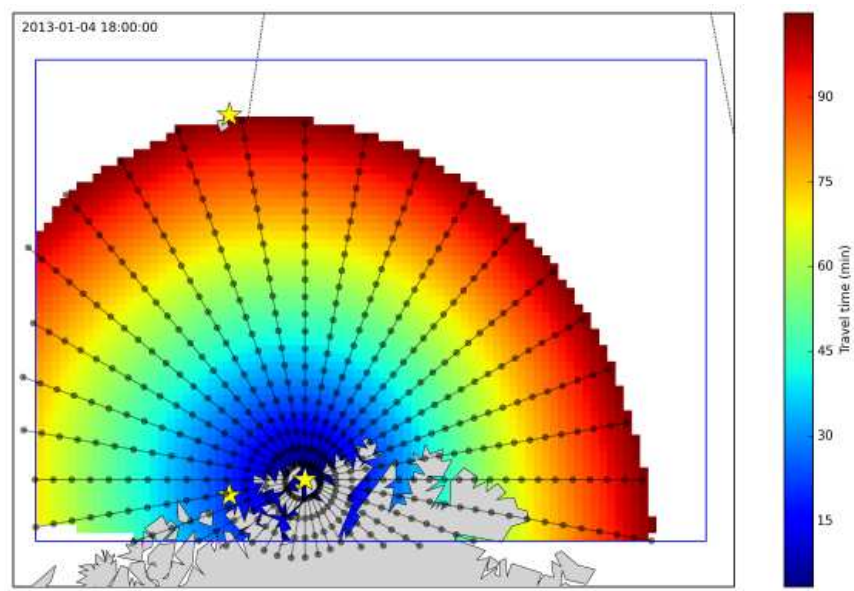

(b) Interpolation of travel times

Figure 3: Transit time calculation 


\section{Brachner}

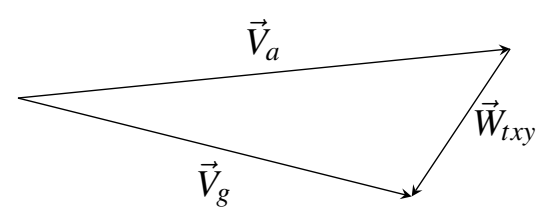

Figure 4: Wind triangle

The simulation follows a constant time step advance mechanism, i.e., the simulation clock is incremented step-wise, moving the RU by a calculated ground vector. For this, the nearest available weather and the daylight data of the current position and time is fetched from the preprocessed data. Based on the environmental data, the ground vector is determined by the wind triangle shown in Figure 4, where $\vec{V}_{a}$ describes the true air movement, $\vec{W}_{t x y}$ designates the wind vector, and $\vec{V}_{g}$ is the vector over ground. While the direction of the ground vector is determined by the planned course of the aircraft $c(n)$, its length is a result of the known $\vec{W}_{t x y}$ and $\vec{V}_{a}$. The length of $\vec{V}_{a}$ is known $\left(\left|\vec{V}_{a}\right|=S_{r}\right)$, but the direction needs to be determined accordingly (see Federal Aviation Administration (2008), p. 15-12). The unit is moved by $\vec{V}_{g}$, and the time is incremented by a constant time step. The new position of the RU and the current time is recorded. The simulation continues by repeatedly advancing the RU until the end of the ray is reached under the aforementioned conditions. Then the RU is reset to its initial location and a new ray with a clockwise rotated course is calculated. This procedure repeats until a full revolution around the initial position has been done.

After simulating the radial travels, the grid points are interpolated by an inverse distance weighting interpolation (Shepard 1968) to the 4 nearest neighbors. The transit time for each resource $r \in R$ of time period $t \in T$ for each point $x, y$ of the grid is written into the Matrix $A_{r t x y}$.

\subsection{Response Simulation}

The response simulation consolidates the transit of different RUs to the incident site and the pick-up of the people in distress. As an output, the response capacity is obtained for each point in time on the grid. This results in a high number of operations needed. For example, the grid in use was $83 \times 59$, with 2,920 time periods for one year. This results in $2,920 * 83 * 59=14,299,240$ responses to be simulated. The response capacity increases as RUs arrive. This capacity is not increasing linearly, as any helicopter, that arrives after the first one, only contributes half of its capacity. This fact of interdependence makes it impossible to just add up the individual capacities of every single RU. This was solved by sorting the transit time matrix $A$ along its resource dimension, resulting in the sorted matrix $A^{\star}$. As an example, if the arrival times at point $(50,30)$ and time period 30 would be $24,15,36$, the ordered list $L=15,24,36$ would represent the sequence, in which the RUs are approaching the incident site.

Given R the set of RUs, the matrix of significant wave heights $H$, the daylight matrix $L$. Then the pickup time matrix $P$ is calculated for every time period $t$ at the position $(x, y)$ in the simulation grid as

$$
P_{t x y}=2+\left(1-L_{t x y}\right)+\frac{1}{6} H_{t x y}
$$

This is a result of a linear interpolation of the points given in Table 1.

Earlier it was mentioned, that additional rescue units arriving on site are not able to contribute their capacity to their full extent, as they will need to coordinate the operation with the other units. This is modeled with the effect matrix $E$, the proportional effect of the arrival of the $r^{\text {th }}$ rescue unit.

$$
1 \geq E_{1} \geq \cdots \geq E_{r} \geq \cdots \geq E_{|R|} \geq 0
$$




\section{Brachner}

Then, the capacity matrix $C$ denotes the number of persons that can be picked up within $t^{\text {max }}$ at an incident happening at a time $t$ and point $(x, y)$ and is the result of

$$
C_{t x y}=\sum_{r=1}^{|R|} \frac{\left(t^{\mathrm{max}}-t^{\mathrm{mob}}-A_{r t x y}^{*}\right) E_{r}}{P_{t x y}}
$$

\subsection{Consolidation}

The resulting capacity matrix can be used to calculate the fraction of time, when a point can be sufficiently covered by RUs. For this, a binary matrix $B$ indicates whether the available resources can contribute the minimum capacity $c^{r e q}$ at point $(x, y)$ and time $t$ :

$$
B_{t x y}= \begin{cases}1 & \text { if } C_{t x y} \geq c^{\text {req }} \\ 0 & \text { otherwise }\end{cases}
$$

The normalized sum over the time axis reflects the proportion, to which a point $(x, y)$ could be covered sufficiently during a time period $\mathrm{T}$.

$$
M_{x y}=\frac{\sum_{t \in T} B_{t x y}}{|T|}
$$

Visualizing the points $(x, y) \mid M_{x y} \geq p$ on a map shows the safe areas, where the coverage is within an accepted threshold $p$.

\section{TECHNICAL REALIZATION}

The simulation was programmed in Python. This environment presented itself as an efficient development platform for the model at hand with powerful abilities to process input data, and simulate and visualize spatial problems. Furthermore, the handling of multidimensional matrices in the form of arrays is very convenient. The computationally expensive parts of the simulation were still written in Python language, but compiled into native machine instructions using Numba (Continuum Analytics 2015).

\section{CASE STUDY}

The presented model was used to conduct experiments in an area of the Barents Sea region, which is delimited to the North and West by the small island Bjørnøya, to the East by the Russian border, and to the south by the city Hammerfest. Figure 5 shows the coordinates in decimal degrees for locations used in this case study. The maximum TAS of the SAR helicopters used as RUs are assumed to be 140 knots. Furthermore, the mobilization time $t^{\mathrm{mob}}$ is 15 minutes, and the maximum time of a man in sea $t^{\mathrm{max}}$ is 120 minutes.

\subsection{Pre-Processing of Environmental Conditions}

For the environmental conditions data from the Norwegian $10 \mathrm{~km}$ Reanalysis Archive (Reistad et al. 2011) for the year 2013 was used. This is hindcast data, providing significant wave height, wind speed and direction on a grid with a resolution of $10 \mathrm{~km}$ every 3 hours. The data is delivered on a rotated spherical grid and had to be regridded to fit the target grid used for the simulation. For the regridding one has to decide how to interpolate the data. For the wind, which is directional data, this can be particularly cumbersome. As Schaefer and Doswell (1979) point out, isolating the vertical and horizontal component of the wind and applying common interpolation techniques on these components separately does not necessarily yield the same as interpolation of magnitude and orientation. Furthermore, interpolating the orientation is ambiguous, as the wind direction can change clockwise or counter-clockwise between two points. The data provided 


\section{Brachner}

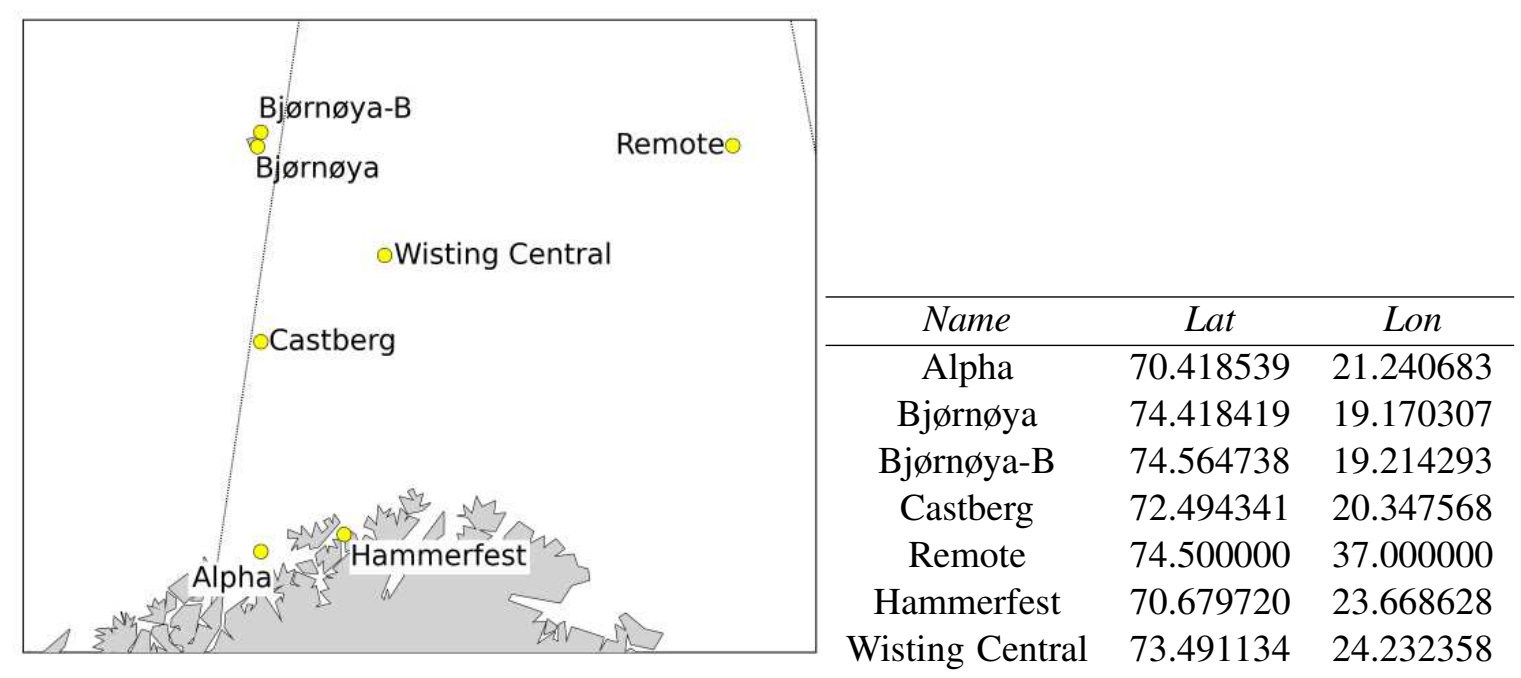

Figure 5: Locations for case study

is already interpolated data on a regular grid without gaps. Additional interpolation, which does not take into account the underlying weather model would not improve the result. For this model regridding by using the nearest neighbor was therefore sufficient. There are, however, interpolation techniques for wind, which could be used in case of missing or too coarse wind data. Ye, Hong, and Wang (2014) provide a recent comparison of different methods. The significant wave height was interpolated by inverse distance weighting.

Finally, daylight is included into the model. This is a computed binary matrix indicating if the sun is above or under the horizon for a given latitude, longitude, time and date. Rising and setting time are calculated using the method given by the U.S. Nautical Almanac Office (2014). It is pointed out, that this method can give somewhat inaccurate results at high latitudes near the dates when the sun remains above or below the horizon for more than 24 hours. The error of few minutes during two very short periods throughout the year is not assumed to influence the result significantly.

\subsection{Experiments}

For the experiments, the simulation was run for each environmental state given for the year 2013. As the time resolution was 3 hours, this resulted in a sample size of 2,920 for each experiment.

It is hypothesized, that not only the interdependence, but also the probability distribution is location dependent (Hypothesis 1). The histograms in Figure 6 show the simulated travel times during the year 2013. It is evident, that the two probability distributions differ significantly. Variance and median of the sample from Bjфrnфya-B are considerably higher than the travel times from Hammerfest.

Hypothesis 2 states, that the travel times of two RUs to an incident site are interdependent, but the interdependency is defined by their location. To test this hypothesis, the scenario visualized earlier in Figure 2 was simulated. Figure 7a shows both RUs located opposite to each other, equidistant to the incident site Castberg. Both the scatterplot and pearson's correlation coefficient show the interdependency. However, the correlation is negative, in contrast to Figure 7b, where the two RUs are located near to each other.

These two facts have important implications, when it comes to the performance and robustness of the ERS. First, according to Hypothesis 1, some locations are favorable, because they have lower median travel times and/or the distribution of travel times is more stable over time. Second, as a consequence of Hypothesis 2, RUs can be located in such a way, that the travel time variation can be partially canceled out if they correlate negatively. 


\section{Brachner}
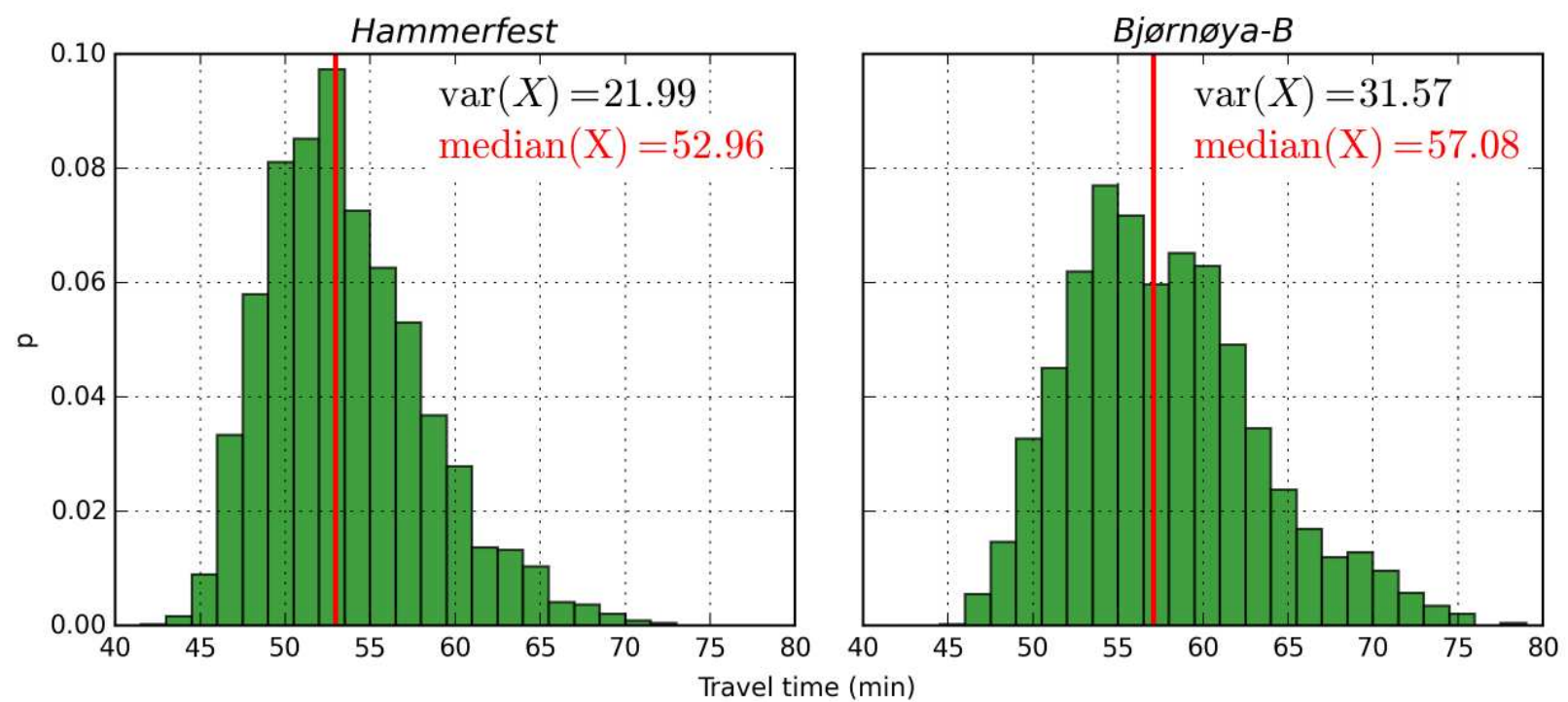

Figure 6: Histogram of simulated travel times from two equidistant locations to Castberg

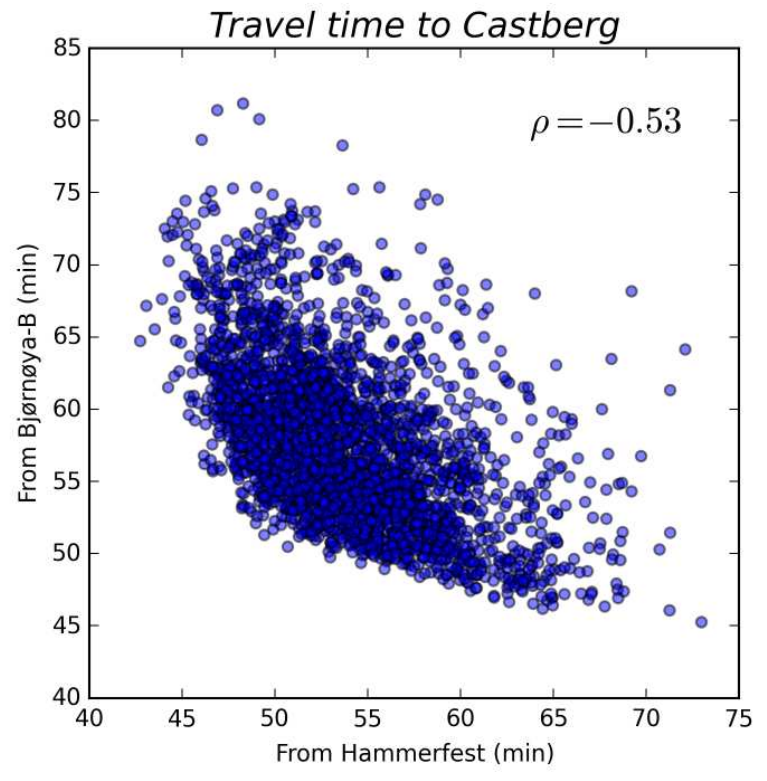

(a)

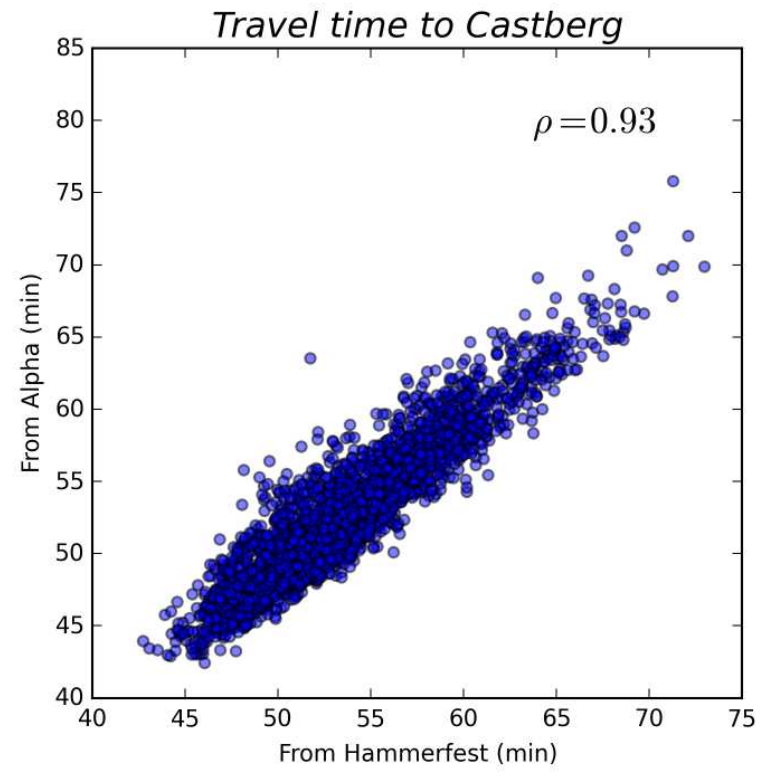

(b)

Figure 7: Scatterplot of simulated travel times from two equidistant locations to Castberg 


\section{Brachner}

These consequences make it even more important to consider emergency preparedness not isolated, but as a system. This system view is shown in Figure 8, where after the simulation run the results were consolidated with Equations 4 and 5, and heat-maps were generated, that show the fraction, at which it was possible to rescue the required number of people at a certain point in the area within 120 minutes throughout the year 2013. In Figure 8a only one RU was positioned at Hammerfest, marked by a star. It is quite striking how small the safe area is. The scenario in Figure $8 \mathrm{~b}$ includes 2 more RUs at Castberg and Remote. Figure 8c involves locating a SAR helicopter at Bjфrnфya - a variant, that has been frequently part of public discussion in Norway (Spitsbergen 2013). While there may be other reasons or assumptions, which support this variant (as, e.g., helicopters that can reach a higher TAS), in the given case this would not be a sound decision. The transports to neither of the three installations could be conducted within the safe area.

A favorable configuration is shown in Figure 8d, where the RU is positioned at a future installation in the Wisting Central area. In this case, a big area could be covered with the given requirements, and transport routes to all three installations would be safe.

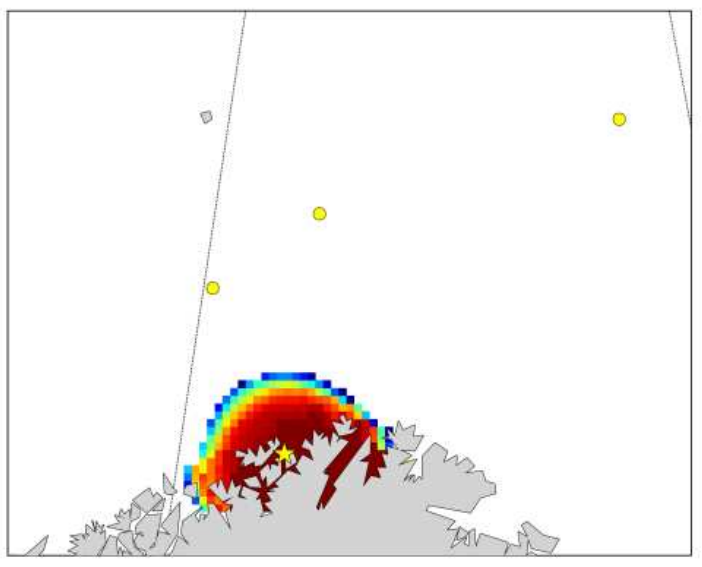

(a)

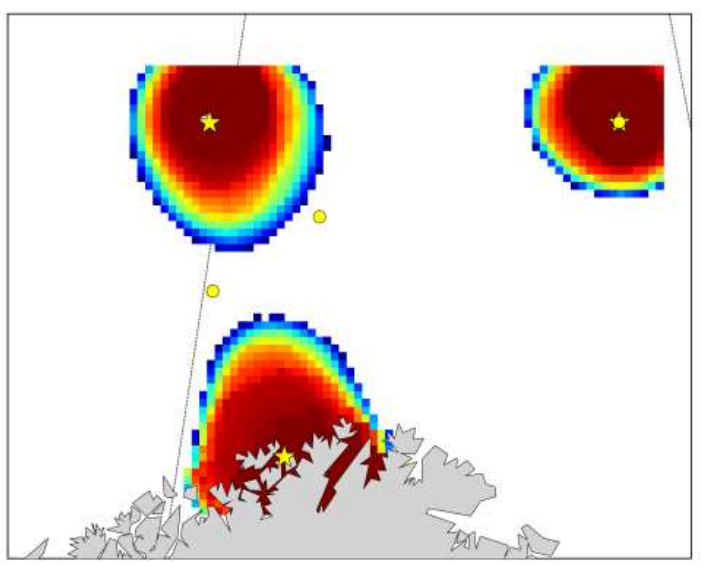

(c)

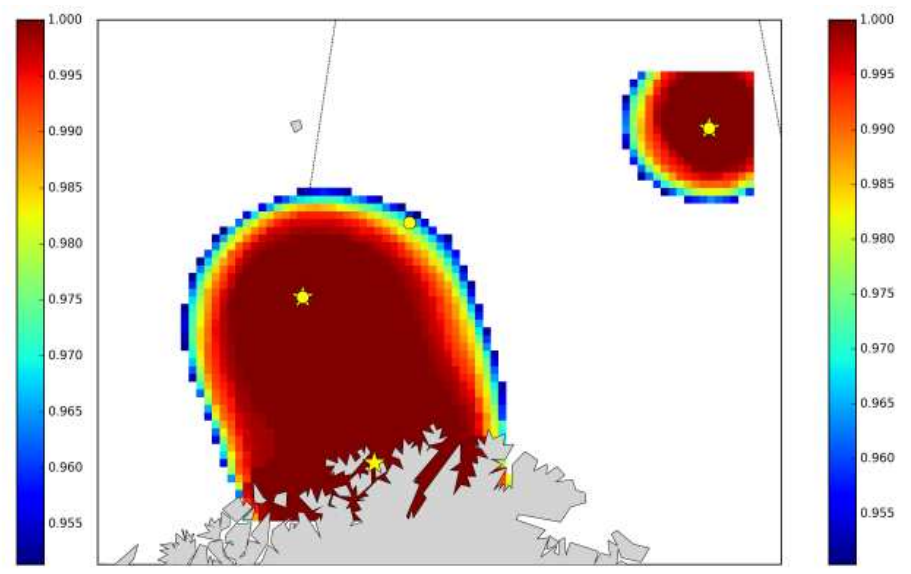

(b)

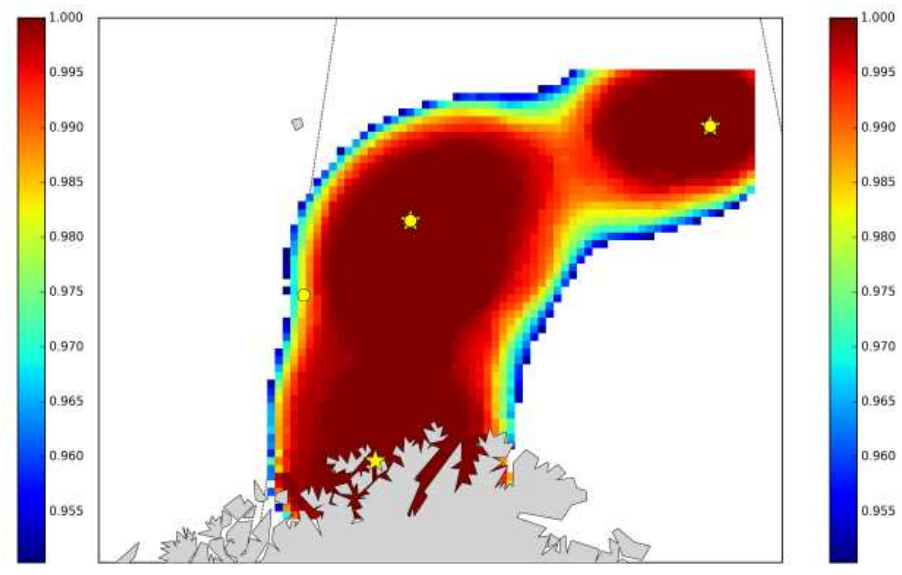

(d)

Figure 8: Safe areas for different scenarios at a threshold $p=0.95$

The run times for the 4 scenarios are reported in Table 2. The interpolation part of the travel time simulation takes the bigger part of the resulting time. If needed there is definitely potential to decrease the run time by optimizing this part. The run times scale linearly with the number of RUs. 


\section{Brachner}

Table 2: Runtimes in seconds for the 4 presented scenarios

\begin{tabular}{ccccc}
\hline Scenario & $\begin{array}{c}\text { Travel time } \\
\text { simulation }\end{array}$ & $\begin{array}{c}\text { Travel time } \\
\text { interpolation }\end{array}$ & $\begin{array}{c}\text { Response simulation } \\
\text { and consolidation }\end{array}$ & Sum \\
\hline (a) & 1 & 45 & 1 & 47 \\
(b) & 3 & 131 & 4 & 138 \\
(c) & 3 & 121 & 4 & 128 \\
(d) & 3 & 146 & 4 & 153
\end{tabular}

\section{CONCLUDING REMARKS}

In this paper the importance of understanding preparedness from a systems perspective was shown. A simulation model for offshore emergency response that evaluates robustness and rescue capability in case of helicopter ditches was presented. This model can be developed in several directions. First, further validation is necessary. This is particularly difficult as very few real incidents have occurred so far that could be taken as a reference. Second, the integration of other stochastic factors, such as, for example mobilization time can be considered. That is also valid for the maximum time in sea which could be replaced by a survival function. Furthermore, nearby ships could be considered as RUs. As there is very low traffic in this area at this time, this will not significantly improve the accuracy. However, as ship traffic is increasing, these would become important rescue resources as well. Finally, applications for this model can be found in other industries as well. Fishing vessels, cargo and cruise ships do have similar issues in the Arctic Region, and the planning of an ERS, that can profit from economies of scale by joining efforts of private and public players like the petroleum industry, coast guard and military is believed to have potential.

\section{ACKNOWLEDGMENTS}

Thanks to the Norwegian Meteorological Institute for providing metocean data. The author would like to thank Harstad University College, DNV-GL and Troms county for their financial support of the research. Furthermore, the author appreciates the valuable feedback and support from his wife Olga Sergeeva.

\section{REFERENCES}

Berman, O., I. Hajizadeh, and D. Krass. 2013. "The maximum covering problem with travel time uncertainty”. IIE Transactions 45 (1): 81-96.

Continuum Analytics 2015. Accessed June 11, 2015. http://numba.pydata.org/.

Federal Aviation Administration 2008. "Pilot's Handbook of Aeronautical Knowledge". Accessed June 11, 2015. http://www.faa.gov/regulations_policies/handbooks_manuals/aviation/pilot_handbook/.

Holthuijsen, L. H. 2007. Waves in oceanic and coastal waters. New York, NY, USA: Cambridge University Press.

Ingolfsson, A., S. Budge, and E. Erkut. 2008. "Optimal ambulance location with random delays and travel times". Health Care Management Science 11 (3): 262-274.

Jacobsen, S. R., and O. T. Gudmestad. 2013. "Long-Range Rescue Capability for Operations in the Barents Sea". In ASME 2013 32nd International Conference on Ocean, Offshore and Arctic Engineering, V006T07A013-V006T07A013. American Society of Mechanical Engineers.

Komen, G. J., L. Cavaleri, M. Donelan, K. Hasselmann, S. Hasselmann, and P. Janssen. 1996. Dynamics and modelling of ocean waves. New York, NY, USA: Cambridge University Press.

Kråkenes, T., S. Håbrekke, I. Wærø, and K. Øien. 2013. "Estimated rescue times for persons from sea”. Technical report, SINTEF. Internal memo.

Li, P., B. Chen, B. Zhang, L. Jing, and J. Zheng. 2014. "Monte Carlo simulation-based dynamic mixed integer nonlinear programming for supporting oil recovery and devices allocation during offshore oil spill responses". Ocean \& Coastal Management 89:58 - 70. 


\section{Brachner}

Li, X., Z. Zhao, X. Zhu, and T. Wyatt. 2011. "Covering models and optimization techniques for emergency response facility location and planning: a review". Mathematical Methods of Operations Research 74 (3): 281-310.

Norrington, L., J. Quigley, A. Russell, and R. Van der Meer. 2008. "Modelling the reliability of search and rescue operations with Bayesian Belief Networks". Reliability Engineering \& System Safety 93 (7): 940-949.

Norsk olje og gass 2012. "Anbefalte retningslinjer for etablering av områdeberedskap". Accessed June 11, 2015. https://www.norskoljeoggass.no/Global/Retningslinjer/HMS/Beredskap/064\%20-\% 20Anbefalte\%20retningslinjer\%20for\%20omr\%C3\%A5deberedskap.pdf. In Norwegian.

Reed, M., O. M. Aamo, and P. S. Daling. 1995. "Quantitative analysis of alternate oil spill response strategies using OSCAR". Spill Science \& Technology Bulletin 2 (1): 67 - 74.

Reistad, M., Ø. Breivik, H. Haakenstad, O. J. Aarnes, B. R. Furevik, and J.-R. Bidlot. 2011. "A highresolution hindcast of wind and waves for the North Sea, the Norwegian Sea, and the Barents Sea". Journal of Geophysical Research: Oceans 116 (C5). C05019.

Schaefer, J. T., and C. A. Doswell. 1979. "On the Interpolation of a Vector Field". Mon. Wea. Rev. 107 (4): 458-476.

Shepard, D. 1968. "A Two-dimensional Interpolation Function for Irregularly-spaced Data". In Proceedings of the 1968 23rd ACM National Conference, ACM '68, 517-524. New York, NY, USA: ACM.

Soma, H., S. Haugen, and B. Øygarden. 2003. "Risk assessment of passenger vessels". In Safety and Reliability: Proceedings of the ESREL 2003 Conference, Maastricht, the Netherlands, 15-18 June 2003, edited by T. BEDFORD and P. van Gelder: CRC Press.

Spitsbergen 2013. "Helicopter base on Bear Island (Bjørnøya)?". Accessed June 11, 2015. http://www. spitsbergen-svalbard.com/2013/10/13/helicopter-base-on-bear-island.html.

U.S. Nautical Almanac Office 2014. Astronomical Almanac for the Year 2015 and Its Companion, The Astronomical Almanac Online. United States Department of Defense.

Vinnem, J. E. 2011. "Evaluation of offshore emergency preparedness in view of rare accidents". Safety Science 49 (2): 178-191.

Vinnem, Jan Erik 2012. "Retningslinjer for områdeberedskap - Underlagsrapport, forutsetninger og faglige vurderinger". Accessed June 11, 2015. https://www.norskoljeoggass.no/Global/Retningslinjer/HMS/ Beredskap/064\%20-\%20Underlagsrapport.pdf. In Norwegian.

Ye, W., H. Hong, and J. Wang. 2014. "Comparison of Spatial Interpolation Methods for Extreme Wind Speeds over Canada". Journal of Computing in Civil Engineering:04014095. doi:10.1061/(ASCE)CP.19435487.0000429.

Yun, G., and A. Marsden. 2010. "Methodology for estimating probability of success of Escape, Evacuation, and Rescue (EER) strategies for arctic offshore facilities". Cold Regions Science and Technology 61 (2-3): $107-115$.

\section{AUTHOR BIOGRAPHIES}

MARKUS BRACHNER is a research scholar at the Department of Business Administration and Social Sciences at the Harstad University College in Norway. He holds a B. Sc. in Software and Information Engineering from the Technichal University in Vienna, Austria, a B. A. in International Logistics Management from the University of Applied Sciences in Steyr, Austria, and a M. Sc. in Industrial Logistics from the Molde University College in Norway. His email address is markus.brachner@hih.no. 